\title{
Carcinoma epidermoide (variante pequenas células) vs. carcinoma de pequenas células do pulmão: diagnóstico diferencial em material de biópsia
}

\author{
Small cell variant of squamous cell carcinoma vs. small cell carcinoma of the lung: differential diagnosis in \\ biopsies
}

Rachel Martins Marinho'; Simone Gusmão Ramos²

unitermos
Câncer pulmonar
Carcinoma epidermoide
Carcinoma pequenas
células
Imuno-histoquímica
Diagnóstico
diferencial

diferencial

\section{resumo}

O diagnóstico diferencial entre a variante pequenas células do carcinoma epidermoide e do carcinoma de pequenas células nem sempre é fácil. Apesar de os descritores alertarem que o primeiro deva manter suas características morfológicas e, muitas vezes, diferenciação escamosa focal, a escassez de material aliada a artefatos de fixação frequentes nessas biópsias podem dificultar a vida do patologista. Entretanto, a definição entre um e outro pode alterar significativamente a escolha da modalidade terapêutica do paciente e, em alguns casos, influenciar seu prognóstico. Procuramos nesta publicação alertar para o problema e facilitar essa diferenciação, sugerindo um painel imuno-histoquímico.

\section{abstract}

The differential diagnosis between small cell variant of squamous carcinoma and small cell carcinoma is not always simple. Despite the fact that studies show the former keeps its morphologic characteristics and focal squamous differentiation, the scarcity of the material as well as frequent fixation artifacts in these biopsies may hinder analysis. However, this differentiation between them may change significantly the choice of therapeutic approach and, in some cases, influence prognosis. In this paper, we draw attention to this problem and suggest a immunohistochemical panel to facilitate this differential diagnosis. Ulltima submissão em 18/01/10 Aceito para publicação em 07/02/10 Publicado em 20/04/10 
Em 2004, a Organização Mundial da Saúde (OMS) reclassificou os tumores primários do pulmão(11), e os carcinomas epidermoides apareceram com algumas variantes, entre elas, a de pequenas células. Essa classificação parece se justificar pelo fato de que carcinomas epidermoides pouco diferenciados podem ser confundidos com o de pequenas células, especialmente em amostras pequenas, prejudicando a evolução do paciente. Embora o prognóstico dos carcinomas pulmonares ainda esteja bem abaixo do desejável, a diferenciação entre os dois grandes grupos de carcinomas (pequenas células $\times$ não pequenas células) modifica substancialmente a modalidade terapêutica escoIhida pelo oncologista. Além disso, enquanto o carcinoma de pequenas células responde razoavelmente a um compêndio quimioterápico (cerca de 50\%), nos carcinomas não pequenas células esse índice parece não ultrapassar 15\%(12).

As neoplasias malignas de células pequenas, redondas e azuis englobam número maior de lesões (Tabela 1) que devem sempre ser consideradas nesses casos, especialmente em amostras pequenas ${ }^{(12)}$. Ao mesmo tempo, o fator limitante (quantidade) da amostra pode justificar maior cautela por parte do patologista quanto à definição da classificação da neoplasia. Vale lembrar que os diagnósticos devem ser confirmados por achados radiológicos e clínicos e que essas informações podem ser fundamentais na separação dessas lesões.

Do ponto de vista anatomopatológico, deve-se considerar que as neoplasias são geralmente classificadas de acordo com sua totalidade, ou seja, tumor ressecado, em que é possível ter várias amostras da lesão $0^{(1,7,8,12)}$. Atualmente, na maioria dos casos os patologistas recebem biópsias endobrônquicas ou transbrônquicas para realização do diagnós- tico, o que certamente limita bastante sua classificação. Nos casos duvidosos, o recomendado é não arriscar e separar (ou pelo menos tentar) entre os dois grandes grupos de neoplasias primárias: pequenas células e não pequenas células. Já nos evidentes, pode-se arriscar mais na classificação da neoplasia, pensando em estudos futuros, em que seja possível avaliar melhor as propostas terapêuticas. No caso do carcinoma epidermoide, geralmente se visualiza algum tipo de diferenciação que sugere o diagnóstico, como pontes intercelulares, células escamoides bem diferenciadas e até mesmo perólas córneas. A limitação nesses casos é representada pelos combinados com adenocarcinomas ou pelo próprio carcinoma de pequenas células, mas essa definição normalmente só seria possível por meio de um golpe de sorte ou com o tumor ressecado em sua totalidade pronto para ser devidamente explorado.

Nessa nova variante, são descritos sinais de diferenciação escamosa ${ }^{(6,14)}$. O problema é se eles estarão ou não presentes em sua amostra. Se estiverem, o diagnóstico é facilitado e a parte pouco diferenciada, se dentro de um contínuo, pode significar áreas menos diferenciadas, justificando o termo variante pequenas células do carcinoma epidermoide. Contudo algumas situações podem complicar. Dúvidas em relação à classificação tumoral podem surgir em alguns casos. Será que aquela área menos diferenciada está mostrando apenas algumas células com grau menor de diferenciação ou são fenotipicamente diferentes? Atualmente, o carcinoma epidermoide tem sido razoavelmente bem decifrado do ponto de vista pré-neoplásico ${ }^{(13)}$. A lesão parece bem relacionada com tabagismo e suas centenas de substâncias tóxicas e evolui de lesões bem diferencia-

\section{Tabela 1 Diagnósticos diferenciais de tumores do tipo pequenas células ${ }^{(12)}$}

Carcinomas brônquicos primários

Carcinoma de pequenas células

Carcinoma epidermoide/variantes basaloide e pequenas células

Linfoma

Mesotelioma

Variante pequenas células

Sarcomas (small round blue cell tumours)

Sarcoma de Ewing/pPNET

Rabdomiossarcoma embrionário

Neuroblastoma e outros tumores primitivos (blastematosos) da infância

Outras lesões pulmonares

Tumourlets

pPNET: tumor neuroectodérmico primitivo periférico. 
das, passando por displasias, até carcinoma in situ e plena invasão. Excelentes revisões recentes estão disponíveis na literatura pertinente $\mathrm{e}^{(7,9,12,13)}$.

Quanto ao carcinoma de pequenas células, o enigma parece continuar. Embora o tabagismo também tenha papel crucial em seu desenvolvimento, não se conhece exatamente sua célula de origem. Lesões neuroendócrinas menos agressivas parecem mais diretamente relacionadas com a presença de hiperplasia de células neuroendócrinas na camada mais basal do epitélio brônquico (alteração pré-neoplásica) do que carcinomas neuroendócrinos. Trabalhos mais antigos os relacionavam com o correspondente brônquico das células de Kulchitsky (neuroendócrinas do epitélio intestinal), mas atualmente a dúvida continua ${ }^{(7,13)}$. O fato de ser positiva para marcadores neuroendócrinos (na maioria das vezes) sugere que sua origem possa ser diferente daquela do carcinoma epidermoide. Entretanto, o achado frequente de tanta heterogeneidade e a sobreposição própria dos tumores primários do pulmão favorecem as alterações genéticas que possam ocorrer em uma célula multipotencial ${ }^{(7,13)}$. Infelizmente, isso ainda não está completamente esclarecido.

Raramente, os tumores pulmonares são ressecáveis quando de sua descoberta. Em geral, carcinoma de pequenas células é tratado com quimioterapia, enquanto o não pequenas células é tratado, se possível, com ressecção cirúrgica ou protocolos quimioterápicos diferentes dos estabelecidos para os de pequenas células. Esse diagnóstico diferencial com base somente em características morfológicas pode ser complicado. Embora a maioria dos carcinomas de pequenas células tenha citoplasma exíguo, bordos celulares indistintos, amoldamento nuclear e cromatina mais delicada que os carcinomas epidermoides pouco diferenciados, essas duas neoplasias dividem aspectos morfológicos com relação a tamanho reduzido da célula, citoplasma escasso e hipercromasia nuclear, às vezes, com nucléolos inconspícuos. Essa sobreposição é particularmente problemática na diferenciação do carcinoma de pequenas células em um padrão de tamanho intermediário (ou quando muito pouco diferenciado) e padrão em grão de aveia. Nessa última condição, a situação pode se complicar pela presença de artefatos frequentes, degenerativos e mecânicos, que podem distorcer a morfologia das células tumorais. Alterações tipo pinçamento (crush), necrose e apoptose nas células tumorais podem tornar obscuros alguns detalhes celulares, especialmente quando se trata do núcleo. Aspectos citológicos podem ser de grande utilidade na diferenciação. $\mathrm{O}$ padrão nuclear típico do carcinoma de pequenas células mostra a cromatina distribuída em um padrão de sal e pimenta, isto é, apresenta grumos de diferentes tamanhos com distribuição relativamente homogênea, enquanto os carcinomas epidermoides mostram padrão de cromatina vesicular e, muitas vezes, nucléolos mais evidentes (Figura). O cuidado deve ser maior ainda em amostras nas quais as células tumorais são escassas. Então, métodos auxiliares são bem-vindos; e o mais accessível em diferentes laboratórios de rotina, atualmente, é a imuno-histoquímica (IMH).

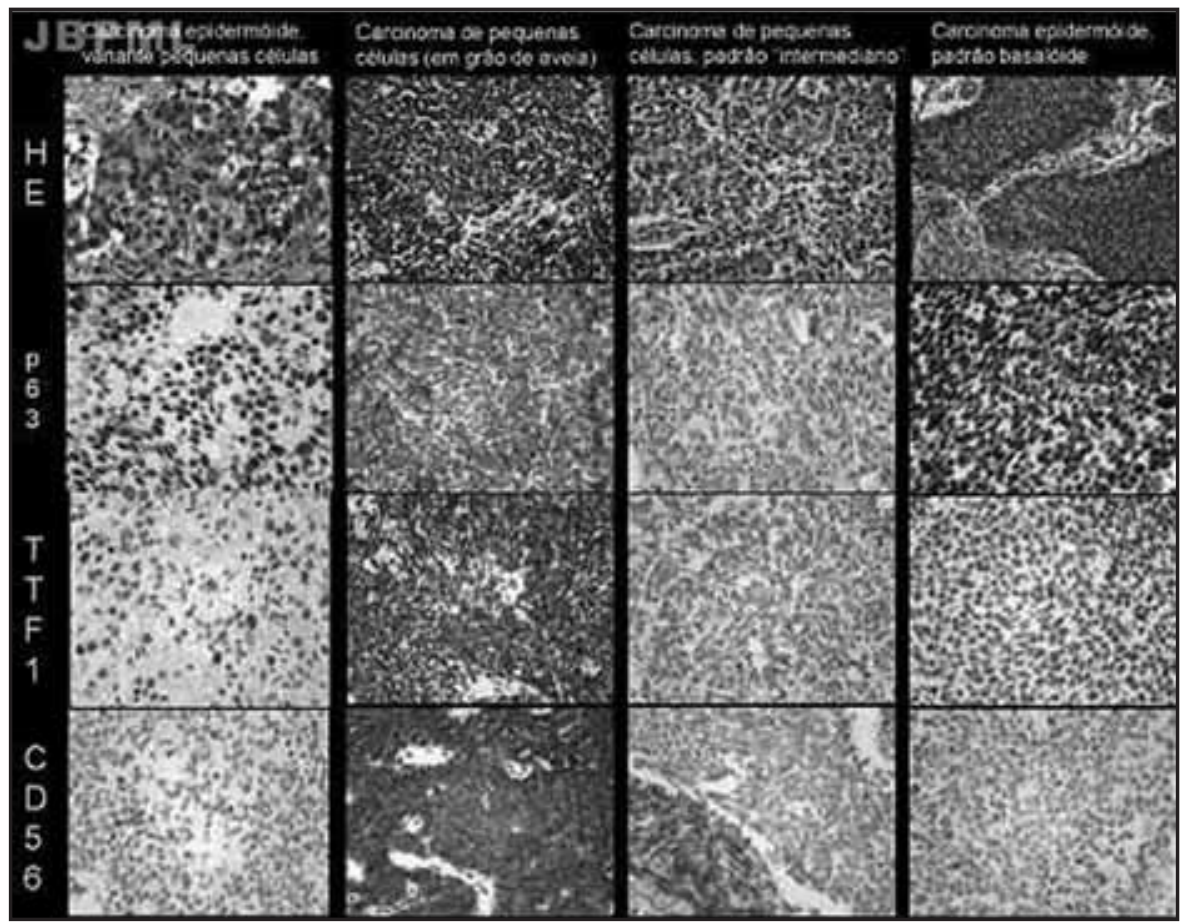

Figura - Painel imuno-histoquímico sugerido na diferenciação do carcinoma epidermoide variante pequenas células com o carcinoma neuroendócrino de pequenas células, tanto no padrão em grão de aveia quanto no intermediário (ressalta-se que desde 1988 os dois tipos não são mais distintos na classificação da OMS). Note o padrão em paliçada característico do carcinoma basaloide, diferenciandoo do epidermoide variante pequenas células 
De fato, lançamos mão da IMH para auxiliar em casos mais complicados. Nem sempre é definitivo, mas geralmente ajuda bastante a direcionar o diagnóstico. A montagem de um painel de anticorpos para IMH nos diagnósticos diferenciais pode aumentar o nível de confidência em melhor classificar a neoplasia ${ }^{(2-5,10,12,14)}$. É importante também garantir a integridade antigênica do tecido estudado, então, alguns autores recomendam utilização de marcadores globais (tipo panceratinas) ${ }^{(2,3,10)}$. Em geral, controles paralelos de qualidade do total das amostras submetidas à IMH são feitos em nosso serviço, por isso esses testes não são individualizados.

Entre os vários marcadores atuais, fator de transcrição da tireoide (TTF-1) e 063 têm sido apontados por recentes publicações como importantes auxiliares nessa separação( $(6,12,14)$. TTF-1 é uma proteína nuclear expressa durante o desenvolvimento da tireoide, do pulmão e de algumas regiões cerebrais. Em pulmões normais, o TTF-1 tem sido observado primariamente no núcleo das células alveolares, particularmente pneumócitos tipo II, células brônquicas não ciliares (células de Clara) e basais. Ele também é expresso em mais de 80\% dos carcinomas de pequenas células originários no pulmão, $39 \%$ dos de pequenas células da bexiga e ainda em uma pequena porcentagem em carcinomas semelhantes, primários do trato gastrointestinal ou ginecológicos, limitando sua utilidade em determinar o sítio primário da lesão $0^{(6,10,12,14)}$. O p63 é um membro da família do gene p53 e suas mutações embrionárias são associadas a graves alterações do desenvolvimento da mama em roedores e humanos. Foram identificadas diversas isoformas do p63, algumas das quais (DNp63) são expressas preferencialmente por células basais de diferentes órgãos, e consideradas possíveis marcadores de células progenitoras/células de reserva. Expressão anormal do $\mathrm{p} 63$ foi originalmente documentada em carcinomas epidermoides da cavidade oral e do esôfago e em lesões pré-malignas e invasivas da cérvix uterina. No epitélio brônquico, ele está positivo em células basais normais, epitélios metaplásico e displásico e carcinomas epidermoides pouco diferenciados. Vale ressaltar que, quando bem diferenciados, esses carcinomas pouco expressam p63. Entretanto, ele pode estar expresso em algumas subpopulações de adenocarcinomas e em tumores neuroendócrinos pouco diferenciados, mas geralmente é negativo em carcinoma de pequenas células $(6,10,12,14)$.

O uso combinado de TTF-1 e p63 tanto em tecidos como em cell block mostram fenótipo TTF-1+/p63- presente em $87 \%$ a $94 \%$ dos carcinomas de pequenas células e fenótipo p63+/TTF-1- em $96 \%$ a $100 \%$ dos carcinomas epidermoides pouco diferenciados ${ }^{(6)}$. Então, a utilização desses marcadores, complementados por outros neuroendócrinos (CD56, cromogranina e sinaptofisina) e acrescidos de marcadores para excluir linfomas (p. ex., antígeno leucocitário comum [LCA], CD45), pode ser de grande valia nessa diferenciação ${ }^{(14)}$. Se possível uma ampliação desse painel, sugerimos CK7 (devido a adenocarcinomas pouco diferenciados) e ceratinas de alto grau ( $34 \beta \mathrm{E}, \mathrm{CK} 5 / 6)$, visto que essas podem auxiliar o p63 na definição da neoplasia. Entretanto, vale lembrar, que TTF-1 e p63 são marcadores nucleares, portanto, mais propensos a resultados confiáveis em neoplasias de citoplasma escasso.

O fenótipo TTF-1+/p63- pode ser expresso em adenocarcinomas, carcinomas de grandes células, em alguns tumores

\section{Tabela 2}

Painel imuno-histoquímico sugerido na diferenciação entre carcinoma epidermoide, variante

\begin{tabular}{ccc}
$\begin{array}{c}\text { Anticorpo/tipo } \\
\text { do tumor }\end{array}$ & $\begin{array}{c}\text { Carcinoma epidermoide variante } \\
\text { pequenas células (\%) }\end{array}$ & $\begin{array}{c}\text { Carcinoma de pequenas } \\
\text { células (\%) }\end{array}$ \\
TTF-1 & ND & 90 a 100 \\
p63 & 90 a 100 & ND \\
CD56 & ND & 60 a 80 \\
Cromogranina & ND & 58 \\
Sinaptofisina & ND & 57 \\
LCA/CD45 & ND & ND \\
$34 \beta E$ & 96 & 7 \\
CK5/6 & 100 & 15 \\
CK7 & 33 & 84 \\
\hline
\end{tabular}

Todas as pontuações referem-se à marcação nas células neoplásicas.

TTF-1: fator de transcrição da tireoide; LCA: leucocyte common antigen; ND: não detectado. 
neuroendócrinos e em carcinomas de pequenas células de outras origens. Nessas situações, alterações citomorfológicas podem ser de grande valia. Resultados TTF-1-/p63- devem alertar para outras neoplasias pouco diferenciadas que entram no diagnóstico diferencial (Tabela 1), ampliando ainda mais o painel imuno-histoquímico. Esse painel também pode ser aplicado em citologias (Tabela 2) ${ }^{(6,12,14)}$. Deve-se ressaltar que nenhuma metodologia ainda é absolutamente definitiva na classificação dessas neoplasias. Alguns tumores caem em uma zona intermediária (gray zone) em que a morfologia e mesmo a IMH não conseguem definir completamente a lesão. Nesses casos, a importância da correlação clinicorradiológica é ainda maior e pode ser crucial na separação dessas duas maiores entidades e dos casos mais difíceis. Por essas razões, esses resultados devem ser considerados dentro de um contexto morfológico, imuno-histoquímico e correlação clinicorradiológica.

Finalmente, a classificação atual da OMS baseia os tumores pulmonares em características basicamente morfológicas dos tumores completamente ressecados ${ }^{(11)}$. Uma das principais dificuldades de utilizar essa classificação se deve ao fato de que, na maioria das vezes, tumores pulmonares são irressecáveis e, portanto, não examinados em sua totalidade, justificando assim o termo genérico carcinoma não pequenas células. Até para patologistas pulmonares, estima-se que em $50 \%$ dos casos não serão encontrados critérios suficientes para classificá-lo como adeno ou epidermoide ${ }^{(12)}$. Mesmo quando esses critérios são encontrados, alguns tumores podem ser reclassificados se estudados em sua totalidade. De toda maneira, os patologistas devem estar atentos à demanda crescente dos oncologistas de melhor classificar os tumores, devido às novas opções terapêuticas. A imuno-histoquímica pode ser de significativa utilidade na separação dos grandes grupos, mas ainda pode falhar na diferenciação mais acu- rada entre os diversos tipos de carcinoma não pequenas células. Por isso, é cada vez maior o interesse de procurar perfis de expressão proteica ou marcadores moleculares nesses tumores. Estudos moleculares têm apontado para alterações genéticas específicas que podem vir a diferenciar tumores e ser utilizadas em terapias-alvo, atuando sobre as células neoplásicas ${ }^{(1,9,12,13)}$.

Em uma revisão de 2005, Cem anos de câncer pulmonar, os autores relataram que historicamente esses tumores tornaram-se problema de saúde pública após as duas grandes guerras, em que o tabaco fazia parte do kit de batalha e era estimulado pelos comandantes ${ }^{(9)}$. A popularização do cigarro ocorreu durante a Primeira Guerra Mundial quando o general John J. "Black Jack" Pershing afirmou: "Perguntem-me o que é necessário para ganhar essa guerra e eu responderei - tabaco e balas"(9). Atualmente, o câncer pulmonar vem declinando nos países desenvolvidos devido a inúmeras confirmações da relação direta do tabaco com diferentes problemas de saúde e, especificamente, com câncer pulmonar. A preocupação atual parece ser maior nos países em desenvolvimento, em que se estima um aumento significativo no consumo de cigarros, especialmente na China, que comporta nos dias atuais cerca de um terço da população fumante mundial(9). Espera-se que o auge dos problemas de saúde em decorrência desse alto consumo ocorra na metade do século XXI. Esperemos que campanhas de prevenção e descobertas na gênese dessas neoplasias contribuam para uma estimativa melhor do que a atual para esses países.

\section{Agradecimentos}

Técnicos de imuno-histoquímica do SERPAT, Ana Beatriz Alcântara Agnesini, Ana Maria Anselmi Dorigan e Osmar Luis da Silva, pela valiosa colaboração.

\section{Referências}

1. ANDREWS, T. D.; WALLACE, W. A.H. Diagnosis and staging of lung and pleural malignancy: an overview of tissue sampling techniques and the implications for pathological assessment. Clinical Oncology, v. 24, n. 6, p. 451-63, 2009.

2. BEASLEY, M. B. Immunohistochemistry of pulmonary and pleural neoplasia. Arch Pathol Lab Med, v. 132, n. 7 , p. 1062-72, 2008.

3. CAPELOZZI, V. L. Role of immunohistochemistry in the diagnosis of lung cancer. J Bras Pneumol, v. 35, n. 4, p. 375-82, 2009.
4. MARSON, V. J. et al. Expression of TTF-1 and cytokeratins in primary and secondary epithelial lung tumours: correlation with histological type and grade. Histopathology, v. 45, n. 2, p. 125-34, 2004.

5. JOHANSSON, L. Histopathologic classification of lung cancer: relevance of cytokeratin and TTF-1 immunophenotyping. Ann Diagn Pathol, v. 8, n. 5, p. 259-67, 2004.

6. KALHOR, N.; ZANDER, D. S.; LIU, J. TTF-1 and p63 for distinguishing pulmonary small-cell carcinoma from poorly differentiated squamous cell carcinoma in 
previously pap-stained cytologic material. Mod Pathol, v. 19, n. 8, p. 1117-23, 2006.

7. LANTUÉJOUL, S. et al. Pulmonary preneoplasia: sequential molecular carcinogenetic events. Histopathology, v. 54 n. 1, p. 43-54, 2009.

8. MOLINA, J. R. et al. Non-small cell lung cancer: epidemiology, risk factors, treatment, and survivorship. Mayo Clin Proc, v. 83, n. 5, p. 584-94, 2008.

9. SPIRO, S. G.; SILVESTRI, G. A. One hundred years of lung cancer. Am J Respir Crit Care Med, v. 172, n. 5 , p. 523-9, 2005.

10. TAN, D.; ZANDER, D. S. Immunohistochemistry for assessment of pulmonary and pleural neoplasms: a review and update. Int J Clin Exp Pathol, v. 1, n. 1, p. 19-31, 2008.
11. TRAVIS, W. D; World Health Organization; International Agency for Research on Cancer; International Association for the Study of Lung Cancer; International Academy of Pathology et al. Pathology and genetics of tumours of the lung, pleura, thymus, and heart. Lyon: IARC Press, 2004.

12. WALLACE, W. A. The challenge of classifying poorly differentiated tumours in the lung. Histopathology, v. 54, n. 1, p. 28-42, 2009.

13. WISTUBA, I. I.; GAZDAR, A. F. Lung cancer preneoplasia. Annu Rev Pathol, v. 1, p. 331-48, 2006.

14. WU, M. et al. p63 and TTF-1 immunostaining. A useful marker panel for distinguishing small cell carcinoma of lung from poorly differentiated squamous cell carcinoma of lung. Am J Clin Pathol, v. 119, n. 5, p. 696-702, 2003. 